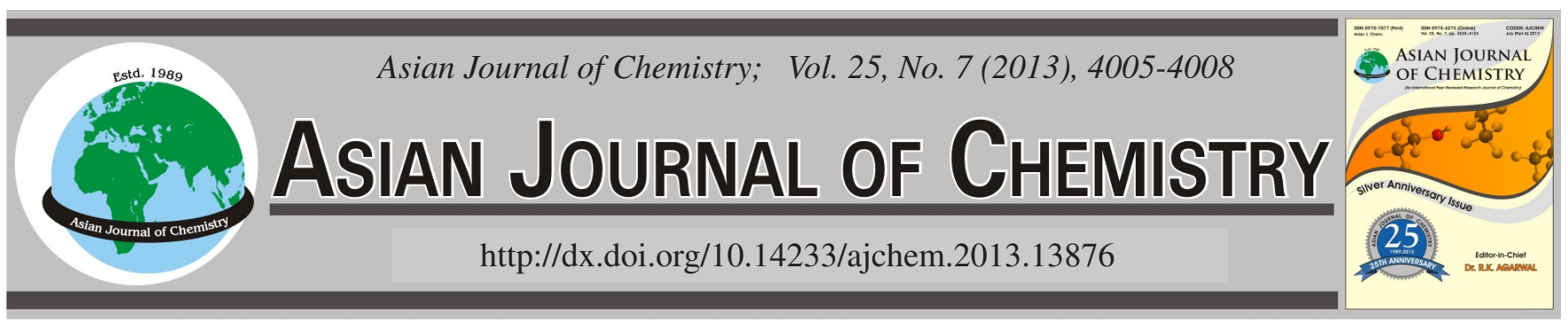

\title{
Catalytic Performance of Ultrastable Y Type Zeolite and Mg-Modified Ultrastable Y Type Zeolite on the Pyrolysis of Neosinocalamus affinis
}

\author{
W.Y. QI, Y. YANG and C.W. Hu*
}

Key Laboratory of Green Chemistry and Technology, Ministry of Education, College of Chemistry, Sichuan University, Chengdu 610064, Sichuan Province, P.R. China

*Corresponding author: E-mail: gchem@scu.edu.cn; chwehu@mail.sc.cninfo.net

(Received: 10 April 2012;

Accepted: 21 January 2013)

AJC-12740

\begin{abstract}
Commercially available ultrastable Y type (USY) and Mg-modified USY (Mg-USY) zeolites have been used in the catalytic pyrolysis of Neosinocalamus affinis respectively, in a fixed bed reactor under nitrogen atmosphere at $773 \mathrm{~K}$. The activity tests showed that the liquid yield increased to $56.4 \%$ and $60.1 \%$ with USY and Mg-USY zeolites respectively, in comparison with that of $25.3 \%$ without catalyst. In particular, Mg-USY catalyst exhibited higher liquefaction activity and resulted in low solid residue of $3.5 \%$ comparing to $28.7 \%$ in non-catalytic experiment. In the presence of USY catalyst, acetic acid was observed as the major component and its content reached $72 \%$ from $37.6 \%$ without catalyst. In the presence of Mg-USY catalyst, the content of acetic acid reduced markedly (to just $25.9 \%$ ), whereas those of 1-hydroxy-2-propanone, 2-furanmethanol and other moderate-molecular weight compounds increased.
\end{abstract}

Key Words: Liquefaction, Mg-modified ultrastable Y type zeolite, Pyrolysis, Neosinocalamus affinis.

\section{INTRODUCTION}

Biomass as a main renewable resource available has received considerable attention and was used as both source of energy and feedstock for organic chemicals ${ }^{1-3}$. The conversion of biomass into energy material can be achieved in a number of ways. Thermochemical processes are thought to have great promise as one technique for efficiently and economically converting biomass to synthetic fuels. Among them, pyrolysis is still the most common, where liquid, gas and solid products are produced and the yields of which are dependant on the reaction conditions ${ }^{4-6}$. In pyrolysis, biomass is heated in the absence of air and broken down into a complex mixture of liquids, gases and residual char. Solid product, char, can be used as fuel either directly as briquettes or as char-oil or charwater slurries, or it can be used as feedstock to prepar activated carbons $^{7,8}$. The gas product having a high calorific value may also be used as a fuel ${ }^{9}$. The most important liquid product, bio-oil, is useful as fuel, which may be added to petroleum refinery feedstock or upgraded by catalysts to produce premium grade refined fuels, or may have a potential use as chemical feedstock ${ }^{10}$.

However, the oil produced by the direct pyrolysis of biomass, due to the high levels of oxygen content, may be highly viscous and corrosive, relatively unstable and exhibit a poor calorific value ${ }^{11,12}$. The leading method used to decrease the percentage of the oxygenated compounds is the catalytic upgrading. So, many studies on the potential recovery of fuels and chemicals from biomass via catalytic pyrolysis in relation to process conditions have been performed ${ }^{13-15}$. Zeolites, silica-alumina, molecular sieves and the like were used as catalysts for upgrading of bio-oil. Although traditional alumina-supported transition-metal sulfide catalysts have high hydrogenation activity, their hydrocracking activity is relatively poor. At present, the hydrocracking catalysts are composed of $\mathrm{Ni}-\mathrm{Mo}$ or Ni-W sulfide species supported on zeolites, to achieve both high activity and flexible selectivity, while there are few studies focused on the catalysts of alkaline-earth metals supported on zeolites for biomass cracking (in situ upgrading) to generate fuels or chemicals ${ }^{16}$.

In our previous work ${ }^{2}$, the pyrolysis of four different kinds of typical bamboos, Neosinocalamus affinis, Pubescens, Bambusa rigida and Dendrocalamus latiflorus, was investigated over $\mathrm{NaY}$ zeolite catalyst, due to their short growth period, strong adaptability to environment and wide distribution in the world. Specially, Neosinocalamus affinis has the highest content of cellulose among the four kinds of bamboos, which is favourable for the formation of carboxylic acid compounds. Therefore, in this work, Neosinocalamus affinis is collected as the raw material in particular. The commercial ultrastable Y type zeolite (USY) and Mg-modified USY zeolites (Mg-USY) are used to investigate their catalytic performance in the liquefaction of Neosinocalamus affinis. 


\section{EXPERIMENTAL}

The sample of Neosinocalamus affinis was collected from Sichuan Province, China. Before the experiments, the sample was dried naturally, ground by a high-speed rotary cutting mill and then prepared to give fractions of $0.1-0.3 \mathrm{~mm}$ mean particle size. The components of Neosinocalamus affinis and residues such as cellulose, hemicellulose and lignin, were analyzed using classical chemical titration methods. The experimental details could be obtained from reference ${ }^{2}$. Table- 1 shows the main characteristics of the biomass pyrolyzed.

\begin{tabular}{|c|c|}
\hline \multicolumn{2}{|c|}{$\begin{array}{c}\text { TABLE-1 } \\
\text { PROPERTIES AND CHEMICAL COMPONENTS } \\
\text { OF Neosinocalamus affinis (wt. \%) }\end{array}$} \\
\hline \multicolumn{2}{|c|}{ Proximate analysis } \\
\hline Moisture & 1.4 \\
\hline Ash & 2.0 \\
\hline Volatiles & 70.6 \\
\hline Fixed carbon & 26.0 \\
\hline \multicolumn{2}{|l|}{ Component analysis } \\
\hline Cellulose & 44.8 \\
\hline Hemicellulose & 21.8 \\
\hline Lignin & 11.9 \\
\hline \multicolumn{2}{|l|}{ Ultimate analysis } \\
\hline $\mathrm{C}$ & 48.6 \\
\hline $\mathrm{H}$ & 6.1 \\
\hline $\mathrm{N}$ & 8.4 \\
\hline $\mathrm{O}^{\text {ah }}$ & 36.9 \\
\hline Heating value $(\mathrm{kJ} / \mathrm{g})$ & 25.38 \\
\hline
\end{tabular}

Catalysts: The commercially available USY catalyst used in the pyrolysis experiments was supplied by Nankai University, China. The Mg-Modified USY catalyst was self-prepared by an incipient wetness method using the commercially USY zeolite as the support. Magnesium nitrate was impregnated onto USY zeolite using incipient wetness method. The impregnated sample was dried at $383 \mathrm{~K}$ in air flow for $2 \mathrm{~h}$. Then the sample was calcined at $773 \mathrm{~K}$ for $4 \mathrm{~h}$. The final sample was designated as Mg-USY and the magnesium loading is 9.7 wt. \% determined by ICP method.

Characterization of the two catalysts: $\mathrm{NH}_{3}$-temperature programmed desorption ( $\mathrm{NH}_{3}$-TPD) measurement was carried out to characterize the surface acidity and acidity distribution of USY and Mg-USY catalysts using gas chromatograph 2000 II. The sample was swept with He flow at $673 \mathrm{~K}$ for $1 \mathrm{~h}$ and then cooled to $373 \mathrm{~K}$. The $\mathrm{NH}_{3}$ adsorption was carried out at $373 \mathrm{~K}_{\text {in }} \mathrm{NH}_{3}$ flow of $15 \mathrm{~mL} \mathrm{~min}^{-1}$ for $1 \mathrm{~h}$ and then the sample was flushed with He flow for another hour. Thereafter, the sample was heated again from $373 \mathrm{~K}$ to $973 \mathrm{~K}$ at the rate of 10 $\mathrm{K} \min ^{-1}$ in He flow.

XRD (X'Pert Pro MPD, Philips, Netherlands) was used to characterize the two zeolite catalysts. The catalyst samples after used in catalytic pyrolysis were also characterized to test if there is any new crystal phase formed. The continuous scanning mode with 0.02 interval and $0.5 \mathrm{~s}$ of set time was used to collect the XRD patterns using $\mathrm{CuK}_{\alpha}(0.15405 \mathrm{~nm})$ radiation operated at $40 \mathrm{~mA}$ and $40 \mathrm{kV}$ over $5-60^{\circ}$ in $2 \theta$.

Pyrolysis: Pyrolysis experiments were performed at 773 $\mathrm{K}$ for $2 \mathrm{~h}$ under $\mathrm{N}_{2}$ atmosphere. $1 \mathrm{~g}$ Sample of Neosinocalamus affinis powder and catalyst (no catalyst or two grams of catalyst) was mixed and then pyrolyzed with a heating rate of $10 \mathrm{~K}$ $\mathrm{min}^{-1}$ in a fixed bed reactor. The temperature of each zone of the furnace was measured by thermocouples (temperature control specialists, SKW-1000). The volatile products were swept out by nitrogen at a flow rate of $28 \mathrm{~mL} \mathrm{~min}^{-1}$ during the experiments. The liquid products were collected in a glass vessel located in an ice trap. Then the liquid product was weighed and recovered in acetone for analysis by gas chromatography-mass spectrometry (Agilent 5973 N GC/MS: column: DB-5, the temperature of the column was maintained at 313 $\mathrm{K}$ for $3 \mathrm{~min}$ and then raised to $453 \mathrm{~K}$ with a ramp rate of $10 \mathrm{~K}$ $\mathrm{min}^{-1}$ and then maintained for $4 \mathrm{~min}$; inlet temperature: 523 $\mathrm{K}$; detector temperature: $523 \mathrm{~K}$; He flow: $0.8 \mathrm{~mL} \mathrm{~min}^{-1}$; mode: split; split ratio: $1 / 25$; injected solution volume: $1 \mu \mathrm{L})$. The residue was also weighted when the temperature was cooled to room scale. The gas yield was determined by overall material balance.

All the yields were calculated on a dry ash free basis and each experiment was repeated three times under the same experimental conditions. The reproducibility of the experimental data was calculated to be within $\pm 0.5 \%$.

\section{RESULTS AND DISCUSSION}

Characterization of zeolite catalysts: Fig. 1 showed the $\mathrm{NH}_{3}$-TPD profiles of USY and Mg-USY zeolite catalysts. The $\mathrm{NH}_{3}$-TPD spectrum of USY showed two low-temperature peaks at about $448 \mathrm{~K}$ and $488 \mathrm{~K}$ and two high-temperature peaks appeared at $561 \mathrm{~K}$ and $618 \mathrm{~K}$. After Mg being supported, the low-temperature peaks disappeared and the high-temperature peaks shift to the medium-temperature. Considering the strength distribution depicted by peak temperature, the acid strength of Mg-USY was lower than that of USY. The lower acid strength of Mg-USY might be attributed to the balance of surface acidity by magnesium. Some studies ${ }^{17,18}$ also indicated that the strong acid sites were influenced by the characteristics of supported metal.

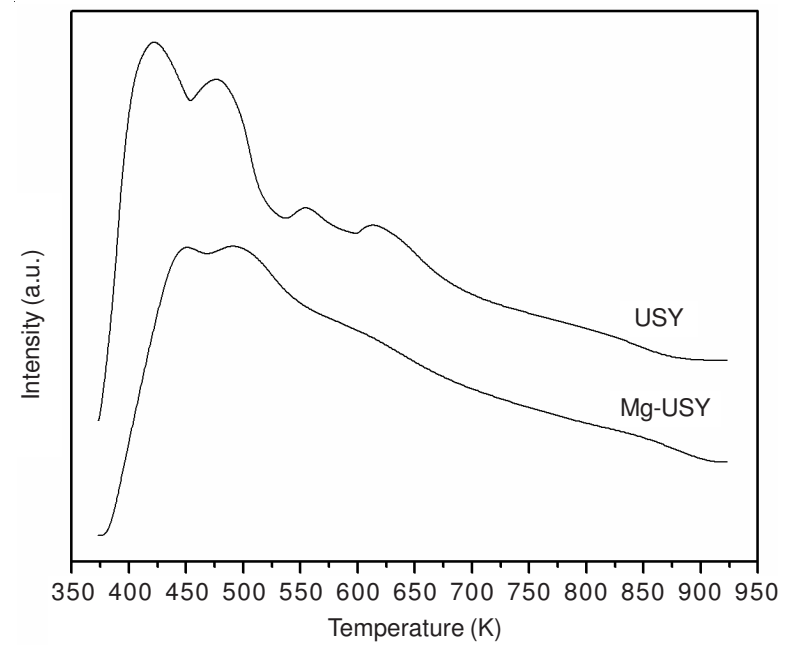

Fig. 1. $\mathrm{NH}_{3}$-TPD profiles of USY and Mg-modified USY zeolite catalysts

Fig. 2 exhibited the XRD patterns of fresh USY, Mg-USY zeolite catalysts and used Mg-USY zeolite named as Mg-USY (Re). A comparison of the patterns of fresh USY and Mg-USY 
showed that there was no new crystal phase formed after $\mathrm{Mg}$ addition. This indicated that magnesium was highly dispersed on the surface of USY zeolite due to the low Mg loading. Combination of this fact with the $\mathrm{NH}_{3}$-TPD results implied that the loading of Mg onto USY zeolite just changed the surface acidity of USY zeolite. The data also indicated that the use of Mg-USY in the pyrolysis of Neosinocalamus affinis did not change the crystal structure of Mg-USY.

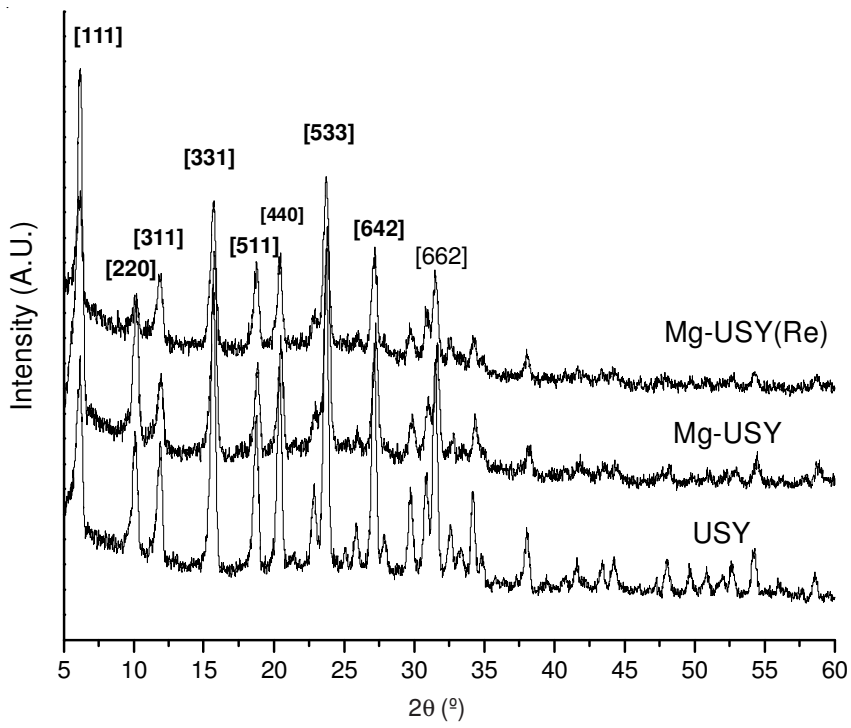

Fig. 2. XRD patterns of fresh USY catalyst, fresh Mg-USY catalyst and residue after used in catalytic pyrolysis with Mg-USY. References 00-011-0672 PDF file

Effect of the catalysts on liquid yield: Activity tests were carried out in an inert atmosphere of nitrogen at $773 \mathrm{~K}$ for $2 \mathrm{~h}$. The distribution of the products with or without catalyst was given in Fig. 3. A comparison of the yield of products showed that in the presence of USY catalyst, the liquid yield increased to $56.4 \%$ from $25.3 \%$. The amount of gaseous products reduced to $19.5 \%$ from $46.0 \%$ and the amount of solid residue reduced to $24.1 \%$ from $28.7 \%$, respectively. In the presence of Mg-USY catalyst, the liquid yield increased sharply, from $25.3 \%$ to $60.1 \%$, while the amount of gaseous products reduced to $36.4 \%$. The amount of solid residues reduced markedly to $3.5 \%$. The results showed that both USY and Mg-USY zeolites could inhibit the formation of solid residues and increase the conversion of Neosinocalamus affinis. MgUSY catalyst was more favourable to produce liquid products than USY. This suggested that the Mg-USY zeolite catalyst exhibited a higher activity in the liquefaction. In our previous work $^{2}, \mathrm{NaY}$ catalyst played a similar role in increasing the liquid yield. The difference was that $\mathrm{NaY}$ catalyst reduced the solid residue to increase both of the gas and liquid products, while the effect of USY and Mg-USY catalysts was just to increase the liquid yield at the expense of both the amounts of gaseous product and solid residue. This indicated that USY and Mg-USY catalysts were more favourable to obtained liquid products in the pyrolysis. Several literatures ${ }^{19-21}$ had reported that other catalysts, such as the Criterion-534 catalyst, activated alumina, klinoptilolite zeolite, dolomite, limestone, etc., could also increase the liquid yield at the expense of both the amounts of gaseous product and solid residue in the pyrolytic processes.

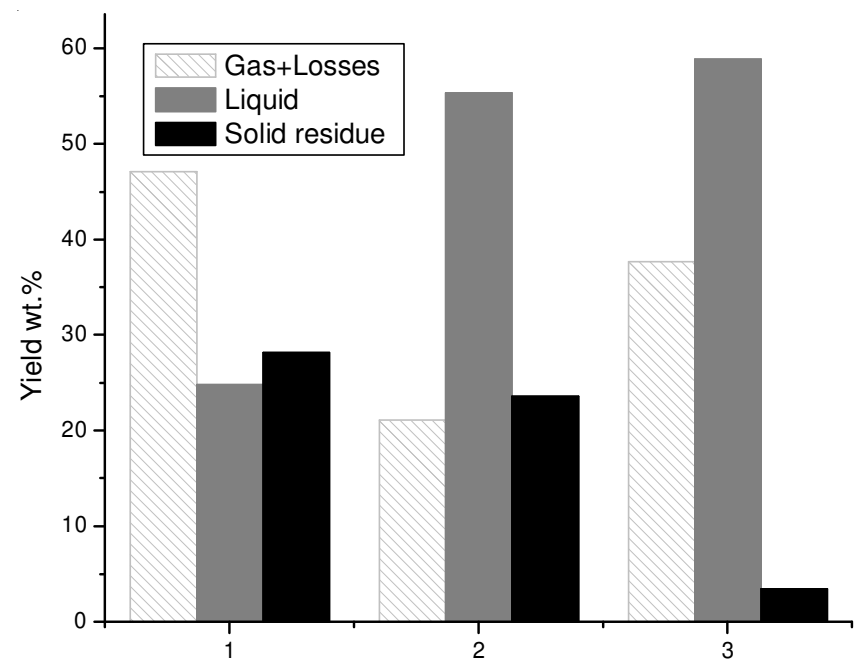

Fig. 3. Distribution of the products over USY and Mg-USY catalysts in comparison with that without catalyst. (1) Without catalyst, (2) USY, (3) Mg-USY

It was obvious that USY and Mg-USY catalysts, under the conditions used, could affect the secondary reactions of the primary pyrolytic intermediates, leading to the increase of liquid. In other words, the increase of liquid yield was not only due to the catalytic cracking effect of the tar but also to the catalytic converting effect of the unstable primary pyrolytic intermediates to liquid products. These unstable primary pyrolytic intermediates would be converted to gaseous C1-C4 hydrocarbons in the absence of catalyst. Rath and Staudinger ${ }^{22}$ assumed that there were three independent parallel reactions, producing three different types of primary tar. In the present work, it was also assumed that the primary intermediates obtained from pyrolysis of Neosinocalamus affinis might be divided into three different types, Inter. I (intermediate species I), Inter. II (intermediate species II) and Inter. III (intermediate species III). During the thermal cracking processes, Inter. I was favourable to be converted into gaseous products, Inter. II into liquid products and Inter. III into solid residues, respectively. The activity data showed that the addition of catalyst could change the scheme by the catalytic effect in the cracking processes. In the presence of USY and Mg-USY, parts of Inter. I and III might be converted catalytically into liquid products to markedly increase the liquid yield. Thus, USY and Mg-USY could enhance effectively the liquefaction of Neosinocalamus affinis.

Effect of the catalysts on the composition of liquid products: The distribution of the liquid composition with and without catalyst for the pyrolysis of Neosinocalamus affinis was compared (Table-2). In the absence of catalyst, the liquid products contained mainly carboxylic, carbonylic, lactonic, phenolic and furan compounds, such as acetic acid, 1-hydroxy2-propanone, 1-hydroxy-2-butanone, butyrolactone, phenol, 2-methoxyphenol, 2,6-dimethoxyphenol, furfural, 2-furanmethanol and 2,3-dihydrobenzofuran. The effects of the two catalysts on the distribution of liquid products were different markedly. In the presence of USY zeolite, acetic acid was a major component, which reached $70.6 \%$ from $36.9 \%$ without catalyst. This was consistent with the role of $\mathrm{NaY}$ zeolite in the previous work ${ }^{2}$. The higher amount of acetic acid might 
TABLE-2

MAIN COMPONENTS IDENTIFIED BY GC/MS IN THE LIQUID PRODUCT WITH OR WITHOUT CATALYST $(\%)^{\mathrm{b}}$

\begin{tabular}{lccc}
\hline \multicolumn{1}{c}{ Component } & $\begin{array}{c}\text { Without } \\
\text { catalyst }\end{array}$ & USY & Mg-USY \\
\hline \multicolumn{1}{c}{ Acetic acid } & 36.9 & 70.6 & 25.4 \\
1-Hydroxy-2-propanone & 4.8 & 1.3 & 8.8 \\
Propanoic acid & - & 5.2 & - \\
1-Hydroxy-2-butanone & 2.3 & - & - \\
Furfural & 9.9 & - & 6.3 \\
2-Furanmethanol & 6.1 & - & 12.8 \\
Butyrolactone & 2.4 & - & - \\
Phenol & 4.1 & 1.0 & 2.6 \\
2-Methoxyphenol & 3.5 & - & 2.8 \\
2,3-Dihydrobenzofuran & 2.7 & - & 1.7 \\
2,6-Dimethoxyphenol & 11.2 & - & 9.5 \\
2-Cyclopenten-1-one & - & 1.5 & - \\
\hline brhe amount (\%) of the products was evaluated through the GC/MS- \\
area; No response factors were introduced.
\end{tabular}

be due to the stronger acid strength (Fig. 1), which favoured the cracking of $\mathrm{C}-\mathrm{C}$ bond, to form the low-molecular weight oxygenated compounds such as acetic acid. Miao et al. ${ }^{23}$ also reported that the $\mathrm{C}-\mathrm{C}$ bond of the hydrocarbon could be broken when the acidity was strong enough. While in the presence of Mg-USY zeolite, the content of acetic acid reduced to $25.4 \%$, the content of 1-hydroxy-2-propanone, 2-furanmethanol and other moderate-molecular weight compounds increased. It showed that Mg-USY zeolite was favourable to the formation of moderate-molecular weight compounds effectively compared to USY zeolite, which could be due to the lower surface acidity. Vitolo et al. ${ }^{24}$ had investigated the catalytic performance of several kinds of zeolite catalysts on the upgrading of bio-oil. They found that the most acidic HZSM-5/50 catalyst produced the maximum yield of upgraded oil at $723 \mathrm{~K}$, whereas the $\mathrm{H}-\mathrm{Y}$ catalyst generally produced higher yields of char, coke and tar. Adjaye and Bakhshi ${ }^{25}$ also reported that HZSM-5 and $\mathrm{H}$-mordenite catalysts produced more aromatics (mainly toluene, xylenes and trimethylbenzenes) than aliphatic hydrocarbons (mainly alkylated cyclopentene, cyclopropane, pentane and hexene), while H-Y, silicalite and silica-alumina produced more aliphatic than aromatic hydrocarbons. In addition, many kinds of commercial catalysts, including zeolites (HZSM-5), fluid catalytic cracking (FCC) catalysts, transition metal catalysts $(\mathrm{Fe} / \mathrm{Cr})$ and alumina, were successfully evaluated in a fixed bed catalytic reactor by Samolada et al. ${ }^{19}$. The results suggested that transition metal catalysts $(\mathrm{Fe} / \mathrm{Cr})$ led to the selective production of phenol and light phenolics. HZSM-5 catalyst was favourable to the production of aromatic hydrocarbons, which was consistent with the results reported by Adjaye and Bakhshi. In this work, it was observed that both USY and Mg-USY zeolites played the role of in situ upgrading catalysts in the catalytic pyrolysis process. USY catalyst was more favourable to the production of aliphatic compounds comparing to non-catalytic run. Mg-USY catalyst exhibited high selectivity to the formation of moderatemolecular weight compounds, while the amount of aliphatic compounds reduced compared to that over USY. The lower content of aliphatic compounds when the alkali earth metals magnesium was supported onto USY zeolite was probably due to the modified surface acidity.

\section{Conclusion}

Both USY and Mg-USY zeolite catalysts could enhance effectively the liquefaction of Neosinocalamus affinis and the liquid yield reached $60.1 \%$ in the presence of Mg-USY catalyst. USY catalyst was favourable to the formation of the lowmolecular weight compounds such as acetic acid. This might be attributed to the higher acid strength of USY. Mg-USY catalyst exhibited high selectivity to the formation of moderatemolecular weight compounds due to the lower acid strength, caused by the balance effect of supported magnesium.

\section{ACKNOWLEDGEMENTS}

This work is financially supported by the National Basic Research Program of China (973 program, No. 2007CB210203) and the Special Research Fund for the Doctoral Program of Higher Education of China (No. 20050610013). The characterization of the catalyst and bio-oils from Analytical and Testing Center of Sichuan University are greatly appreciated. The supervision of academician Qingshi Zhu is highly acknowledged.

\section{REFERENCES}

1. K. Gadgil and K. Sharma, Asian J. Chem., 17, 2710 (2005).

2. W.Y. Qi, C.W. Hu, G.Y. Li, L.H. Guo, Y. Yang, J. Luo, X. Miao and Y. Du, Green Chem., 8, 183 (2006).

3. P. Wang, S.H. Zhan, H.B. Yu, X.F. Xue and N. Hong, Bioresour. Technol., 101, 3236 (2010).

4. E. Pütün, Energy, 35, 2761 (2010).

5. H.L. Chum and R.P. Overend, Fuel Process. Technol., 71, 187 (2001).

6. J.A. Caballero, A. Marcilla and J.A. Conesa, J. Anal. Appl. Pyrol., 44, 75 (1997).

7. F. Suarez-Garcia, A.M. Alonso and J.M.D. Tascon, J. Anal. Appl. Pyrol., 62, 93 (2002).

8. P.T. Williams and S. Besler, Fuel, 72, 151 (1993).

9. D. Meier and O. Faix, Biosour. Technol., 68, 71 (1999).

10. S. Czernik and A.V. Bridgwater, Energy Fuels, 18, 590 (2004).

11. I.N. Slam and F.N. Ani, Bioresour. Technol., 73, 67 (2000).

12. D.J. Mihalcik, C.A. Mullen and A.A. Boateng, J. Anal. Appl. Pyrol., 92, 224 (2011).

13. D. Sutton, B. Kelleher and J.R.H. Ross, Fuel Process. Technol., 73, 155 (2001).

14. E.G. KhamLich and L. Belkbir, Asian J. Chem., 12, 941 (2000).

15. D. Mohan, C.U. Pittman and P.H. Steele, Energy Fuels, 20, 848 (2006).

16. Y.D. Wang, A.M. Zhang, Q.H. Xu and R.Z. Chen, Appl. Catal. A, 214, 167 (2001).

17. D. Li, A. Nishijima and D.E. Morris, J. Catal., 182, 339 (1999).

18. D.Y.C. Leung, X.L. Yin, Z.L. Zhao, B.Y. Xu and Y. Chen, Fuel Process. Technol., 79, 141 (2002).

19. M.C. Samolada, A. Papafotica and I.A. Vasalos, Energy Fuels, 14, 1161 (2000).

20. A.E. Borgund and T. Barth, Org. Geochem., 30, 1517 (1999).

21. F. Ates, A.E. Putun and E. Putun, Energy Convers. Manage., 46, 421 (2005).

22. J. Rath and G. Staudinger, Fuel, 80, 1379 (2001).

23. J.Y. Miao, L.F. Yang and J.X. Cai, Surf. Interf. Anal., 28, 123 (1999).

24. S. Vitolo, M. Seggiani, P. Frediani, G. Ambrosini and L. Politi, Fuel, 78, 1147 (1999).

25. J.D. Adjaye and N.N. Bakhshi, Fuel Process. Technol., 45, 161 (1995). 